\title{
ROSAL Y COLET, DOS INTERIORES HISTORICISTAS DE SANTIAGO MARCO EN LA CASA COMPANY
}

\author{
ROSAL AND COLET, TWO HISTORICIST INTERIORS \\ BY SANTIAGO MARCO IN THE CASA COMPANY
}

\author{
Guillem Masalles Arnavat* \\ Historiador del arte \\ Restaurador de bienes culturales
}

\section{Resumen}

Santiago Marco (1885-1949) fue, indiscutiblemente, unos de los decoradores más importantes de la primera mitad de siglo XX en Catalunya. Presidente del FAD (Foment de les Arts Decoratives) durante 27 años, fue referente en la creación de espacios tanto públicos como privados. Su faceta de actuación más conocida se inscribe en el movimiento "art decó", pero en realidad, Santiago Marco era un profesional que sabía interpretar los gustos, necesidades y expectativas sociales de sus clientes. Esta investigación se centra en dos intervenciones realizadas por Santiago Marco en la Casa Company, una en 1920 y otra en 1942. Se describen las intervenciones y se explican las razones porque ambas fueron de carácter historicista, en qué se inspiró para llevarlas a cabo y quienes colaboraron con el famoso decorador.

Palabras clave: Santiago Marco, Casa Company, Barcelona, Catalunya, Antoni Campanyà, Foment de les Arts Decoratives (FAD).

\section{Abstract}

Santiago Marco (1885-1949) was, indisputably, one of the most important decorators of the first half of the 20th century in Catalonia. Being the President of the FAD (Foment de les Arts Decoratives) for 27 years, he was a benchmark in the creation of both public and private spaces. His best-known facet is that which is part of the art deco movement, but in reality, Santiago Marco was a professional who knew how to interpret the tastes, needs and social expectations of his clients. This research focuses on the two interventions made by Santiago Marco in the Casa Company, one in 1920 and the other in 1942; trying to explain how they were, the reasons why both interventions were historicist, what was his inspiration to carry them out and who collaborated with the famous decorator.

Keywords: Santiago Marco, Casa Company, Barcelona, Catalunya, Antoni Campanyà, Foment de les Arts Decoratives (FAD). 


\section{Introducción}

El Museu de l'Esport Doctor Melcior Colet, ubicado en la calle Buenos Aires 56-58 de Barcelona, es objeto hoy en día de una profunda restauración y rehabilitación, al amparo de un nuevo proyecto museográfico para explicar el deporte catalán a lo largo de los siglos XX y XXI. El museo nació a partir de la donación que realizó en 1982 el último propietario del edificio, el doctor Melcior Colet, al Ayuntamiento de Barcelona, con la condición que se ubicara un museo dedicado al deporte. En 1986 se inauguró el nuevo museo, después de una restauración llevada a cabo por Joan Bassegoda i Nonell (1930-2012) en el año 1983, con la voluntad de recuperar el aspecto original del edifico.

La dirección del Museo, con la señora Mònica Amat a la cabeza, solicitó asesoramiento de la doctora Mónica Piera para encontrar ubicación al mobiliario del Museo, pues a priori, pocas piezas se incorporarían a la exposición museográfica permanente. Se ha conjeturado que la decoración y distribución de las piezas de muebles era obra de Santiago Marco, razón por la cual sería interesante documentarlas. En estas circunstancias, la doctora Mónica Piera me propuso estudiar el tema; propuesta a la que accedí sin dudar.

El interés del estudio radica en el hecho que las intervenciones de Santiago Marco en la casa pertenecen a dos momentos muy diferentes de su trayectoria, pero unidas por el hilo conductor del historicismo: la primera es de estilo renacimiento español, mientras que la segunda remite a los "luises" franceses. En las dos intervenciones, Santiago Marco no se arriesgó, puesto que acudió a referentes que le habían funcionado bien con anterioridad. También se pone en evidencia la importancia que tenía el FAD como vertebrador de una red de proveedores y contactos entre sus asociados.

Para evitar errores de atribución, este estudio parte, sobre todo, de material gráfico de la época - planos y fotografías - además de documentación de archivo. De esta manera, se puede atribuir la autoría de las piezas con poco margen de error. Otras piezas, a pesar de que han llegado hasta nosotros, se han excluido del estudio al no aparecer en la documentación de la época.

\section{Las vidas del núm. 56-58 de la calle Buenos Aires}

\subsection{La Casa Company (1911-1920). Obra de Puig i Cadafalch}

Es poco lo que sabemos de Pere Company Molins (¿? -19221), industrial activo en la vida de la Barcelona burguesa, socio del Sports men's Club Barcelona ${ }^{2}$, vicepresidente ${ }^{3}$ y presidente ${ }^{4}$ de la sección de Industria del Ateneu Barcelonès ${ }^{5}$ y cónsul de la República del Perú desde $1907^{6}$.

En 1910 su esposa, la también poco conocida Maria Company Puig, compró un terreno en el distrito de Gràcia, entre las calles Casanova y Buenos Aires de Barcelona. Un año más tarde, Pere Company encargó al famoso arquitecto Josep Puig i Cadafalch (1867-1956) la construcción de una casa unifamiliar. Por la documentación consultada, parece que esta casa no fue su residencia habitual ${ }^{7}$. 
Puig i Cadafalch estaba inmerso en su etapa blanca, caracterizada por el idealismo racionalista, y redactó un proyecto que el crítico de arte Alexandre Cirici (1914-1983) consideró el más secesionista de esta etapa del arquitecto: la Casa Pere Company (fig.1).

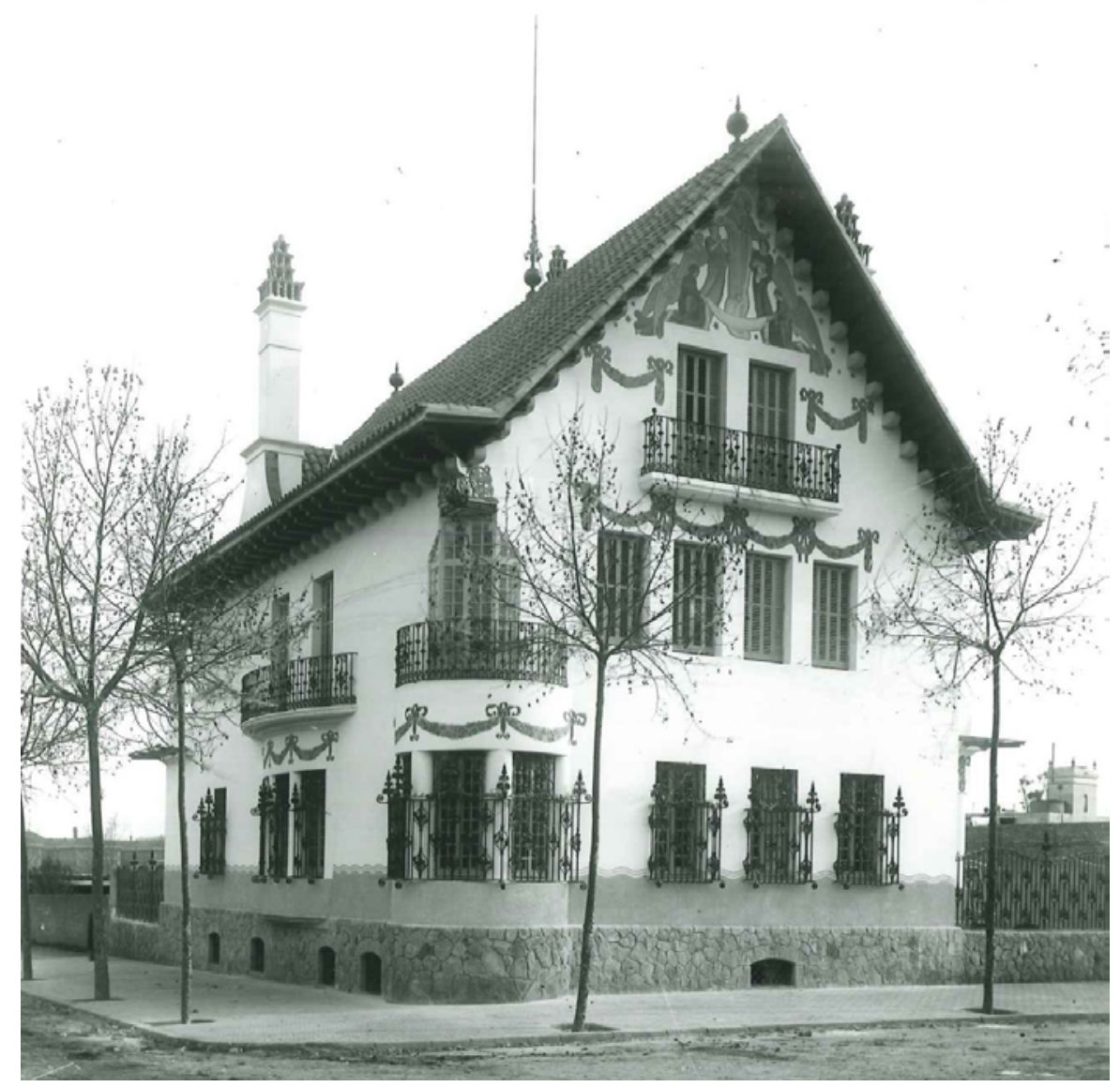

Fig.1: La Casa Pere Company.

Era una casa a cuatro vientos con una cubierta a dos aguas, con dos niveles de tribunas en la esquina de la calle Buenos Aires y Casanova. A nivel ornamental destacan las columnas sin capiteles, los trabajos de forja de Manuel Ballarín (1853-1915) y los esgrafiados de guirnaldas barrocas en las ventanas, pero también los de la Asunción de María y un San Miguel, situados ambos en el tímpano de la casa, obra de Manuel Fontanals (1893-1972). Todos ellos eran colaboradores habituales de Puig i Cadafalch.

Los planos de la casa se conservan en el Archivo Municipal Contemporáneo de Barcelona (expediente de obras 12.724), por lo que podemos conocer la distribución interior. Por desgracia no disponemos de documentación fotográfica del interior, y al estar el edificio aún en restauración, no puede descartarse el descubrimiento de nuevos elementos modernistas, extremo que puede sugerir otras hipótesis. No ahondaré ni especularé sobre cómo era este interior, más allá de la existencia de la conocida chimenea rinconera y de las vigas policromadas. 
La Casa Company fue propuesta para el premio de arquitectura municipal de 1911, promovido por el ayuntamiento de Barcelona; pero aquel año resultó ganadora otra obra de Puig i Cadafalch, la fábrica Casaramona.

2.2. El Chalet de la familia Rosal (1920-1936). El arquitecto Enric Sagnier y Santiago Marco

Por motivos desconocidos, los Company vendieron la casa en 1920 a María Dolores Catarineu Ferran (¿? -1928), conocida por aquel entonces como la "Viuda de Rosal".

Era "dama noble de la reina María Luisa" 8 y pertenecía a la alta burguesía de la ciudad. Hija de Ramon Catarineu i Castells, director de la colonia textil de Can Bros en Martorell ${ }^{9}$, y de Francesca Ferran Dalmases. Maria Dolores Catarineu tenía inquietudes artísticas ya que expuso sus pinturas en la Sala Parés de Barcelona en 1897 y $1899^{10}$. Se había casado con Antonio Rosal Sala ${ }^{11}$ (1852-1911) político y propietario, junto con sus hermanos, de la colonia textil Cal Rosal en Berga, con el nombre de Rosal Hermanos ${ }^{12}$. Ella murió en 1928, dejando la casa a sus ocho hijos, constituidos entonces como Manufacturas Rosal.

En 1920, el mismo año en que María Dolores Catarnieu había comprado la casa, encargó a Enric Sagnier i Villavecchia (1858-1931) una ampliación del edificio. Así, se colocó un nuevo cuerpo de fachada (fig.2: 3.1-3.2) en la Calle Casanovas creando un único acceso por la calle Buenos Aires, tal y como se puede observar en los planos de la licencia de obras (expediente 20.768). Aunque no queda recogido en la documentación, aparte de estas obras se reformó íntegramente el interior de la finca.
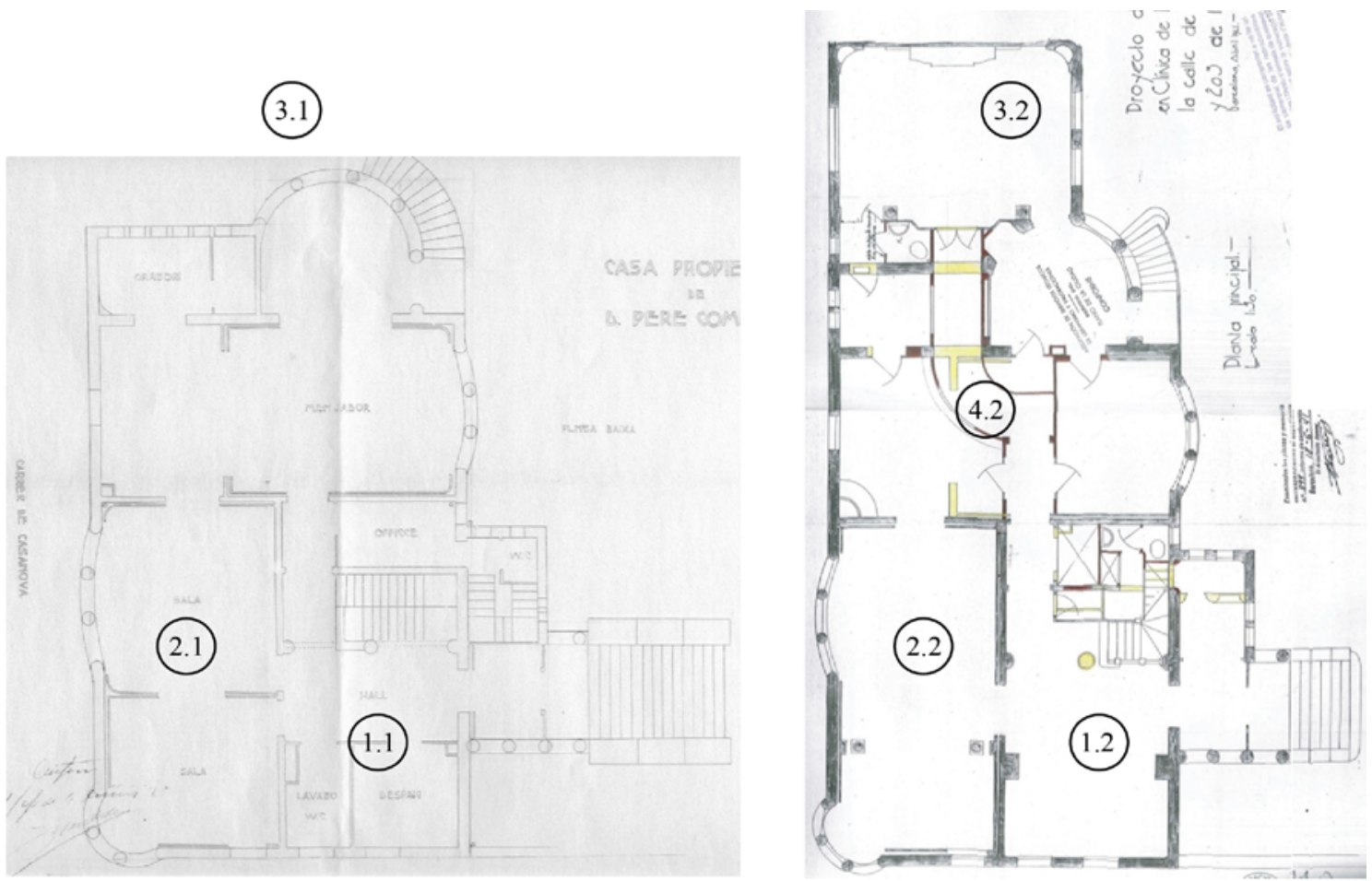

Fig.2: Izquierda: Plano de Puig y Cadafalch (1911). Derecha: Plano de la reforma de Matas y Homs (1941), se aprecian las reformas de 1920. Conservados en el AMCB. 
Consultando el archivo de proyectos ${ }^{13}$ de Santiago Marco i Urrútia (18851949), aparecen dos fotografías con la anotación "Viuda Rosal" en las que se reconoce el vestíbulo de la casa (fig.3). Deducimos, por tanto, que en la ampliación de 1920 de Enric Sagnier los interiores se encargaron a Santiago Marco.
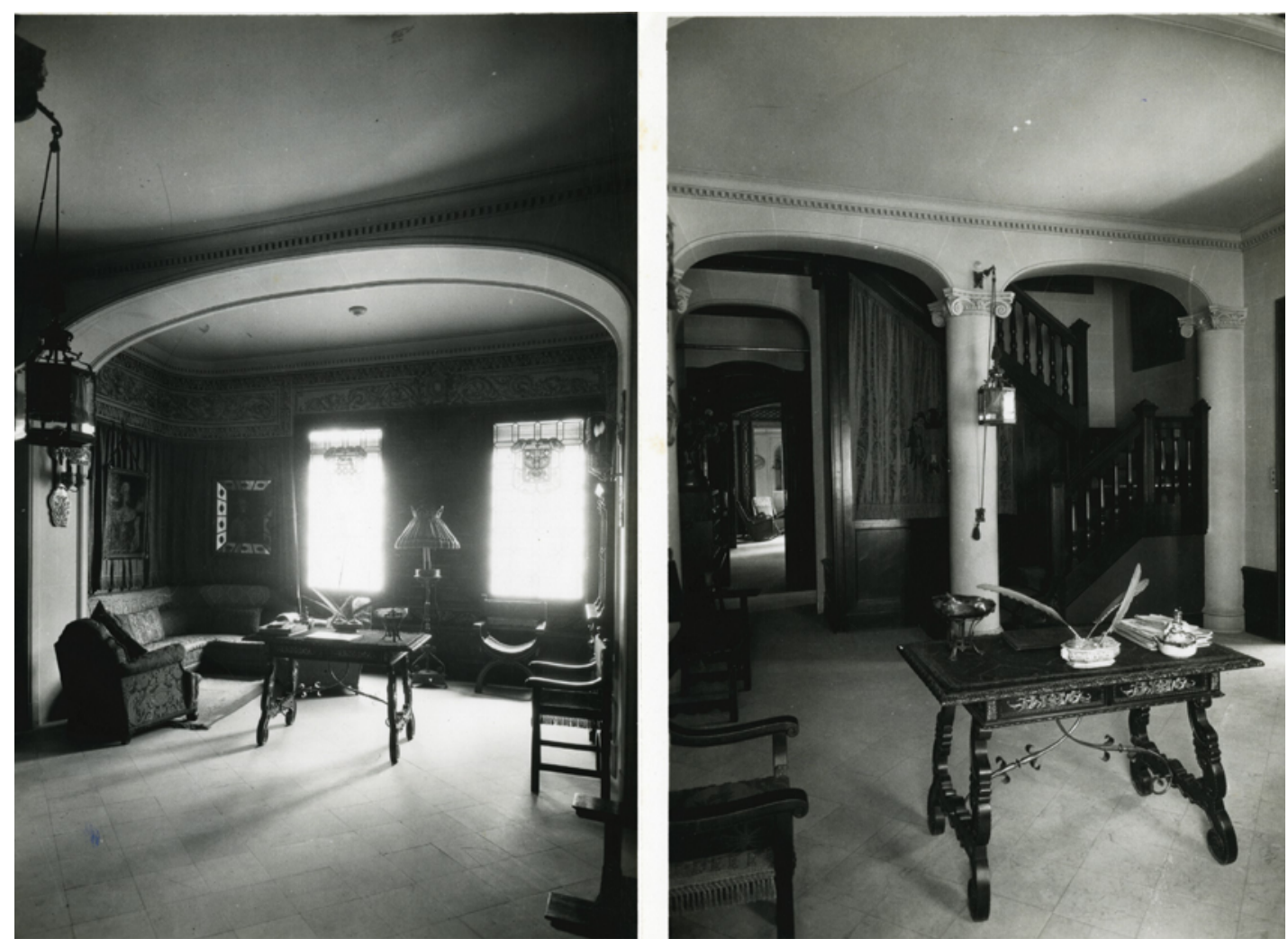

Fig.3: El Vestíbulo de la Casa Rosal. Izquierda (FAD-FT0012-59-A-I). Derecha (FAD-FT0012-59-A-S).

Santiago Marco empezó a trabajar con 14 años en el taller del vidriero Antoni Rigalt i Blanch (1850-1914) para formarse en un oficio; al cabo de 2 años entró al servicio del reconocido mueblista Francesc Vidal Jevellí (1848-1914) como ayudante personal, combinando ese trabajo con la formación nocturna en la Escola Llotja de Barcelona. Después de una temporada viviendo en México y trabajando con el vitralero Wenwooe, se convirtió en el hombre de confianza de Francesc Vidal. Después de la muerte de éste, permaneció en la empresa de su hijo, Frederic Vidal Puig (1882-1950) hasta 1917, momento en que decidió establecerse por su cuenta.

Los interiores del chalet Rosal fueron uno de los primeros trabajos de Santiago Marco en solitario. Esta primera etapa de Marco se caracteriza por el historicismo, estilo al que la burguesía tenía tanto apego. Querían emular un pasado aristocrático, crear espacios de representación pública, de manera que en una misma casa podríamos encontrar un vestíbulo de estilo renacimiento y salones de estilos luises franceses, reservando para otras estancias más privadas estilos más modernos. La casa de los Rosal no será una excepción.

Para comprender la envergadura de la reforma, hay que comparar el plano de Puig i Cadafalch de 1911 con el que realizado en 1941 para la reforma 
de Matas y Homs. Con la documentación citada, se puede afirmar que Santiago Marco participó como mínimo en tres espacios de la casa: el vestíbulo (fig.2, 1.2), la sala (fig.2,2.2) y el comedor (fig.2, 1.3), aunque lo más probable es que interviniera en toda la casa y no sólo en estas tres estancias.

\subsubsection{Vestíbulo}

Observando los planos y las fotografías de proyectos de Santiago Marco, vemos que en esta reforma se engrandeció el hall o vestíbulo para generar dos espacios que, si bien quedan diferenciados, consiguen una relación muy fluida y harmónica a través de la repetición de elementos, como son los arcos de tres centros y los frisos denticulares que recorren la parte superior de las paredes.

Por un lado, se eliminó un despacho y un lavabo (fig.2, 1.1) que había proyectado Puig i Cadafalch, para crear una sala de espera en la que se accede mediante un gran arco de tres centros (fig.2,1.2). Este nuevo espacio recibe luz natural de la calle a través de dos ventanas con vitrales que quedan unificadas con un panel de carpintería casetonada. Los vitrales datan de esta época y guardan la misma relación estilística con otros que pertenecen a proyectos de Santiago Marco, los de la casa Jaume Ballet de 1920.Todos ellos representan motivos heráldicos dentro de unos cueros recortados y con la misma disposición de los plomos y los cristales del fondo. Sobre los vitrales que nos ocupan, en uno se representan dos niveles de leones con un ajedrezado en el medio, mientras que en el otro aparece un águila con las alas extendidas, unas estrellas en los vértices y un fondo con la senyera.

Las paredes de la sala se cubren con telas muy tupidas, buscando plasticidad, volumen y calidez, que contrastan con un friso corrido pintado en la parte superior de la pared, recreando cenefas y paneles de hojas de acanto de aire renacentista. Sobre las telas cuelgan dos cuadros. Encontramos todos estos recursos en otras intervenciones de Santiago Marco, como en la Casa de Ignacio Soler, pero especialmente en su casa personal, que servirá de campo de pruebas para sus proyectos (fig.4).

El mobiliario es básicamente de estilo renacimiento español, con una mesa de fiadores, sillas de jamuga, fraileros, un escritorio, etc., combinado con muebles de confort como un sofá rinconero y unas butacas, tapizados con damascos. El aprovechamiento de tribunas y rincones con cortinas para colocar sofás también es habitual, como en la Casa Agustín Sensat, inclusive se constata en la casa que Santiago Marco tenía en Vilanova i la Geltrú (Barcelona) de 1922; sería lo que el crítico y teórico del arte Joaquim Folch i Torres (1886-1963) consideraría un "racó com nius avellutats"14.

Algunas de las piezas de muebles expuestas en la casa eran antigüedades que se combinaban con reinterpretaciones del momento, algo típico en la época y especialmente en Marco, quien tenía mucha sensibilidad con el pasado y su conservación. Especialmente interesante es el aspecto de las mesas en varios de los vestíbulos de Santiago Marco, pues parece querer recrear un tipo de bodegón conocido como el de mesas revueltas, con papeles, plumas y tinteros.

Enfrente de la sala de espera encontramos un pasillo y la escalera, presidida por una pareja de arcos de tres centros, sustentados por tres capiteles de 
estilo jónico moderno con columnas lisas. Si bien en el plano de Puig i Cadafalch se aprecia una pareja de arcos presidiendo la escalera, muy posiblemente no se trate de los que se ven en la fotografía del vestíbulo de 1920. Además, el hallazgo reciente de vigas policromadas en esta zona dificulta imaginar unas vigas modernistas inscritas en un entorno clasicista.
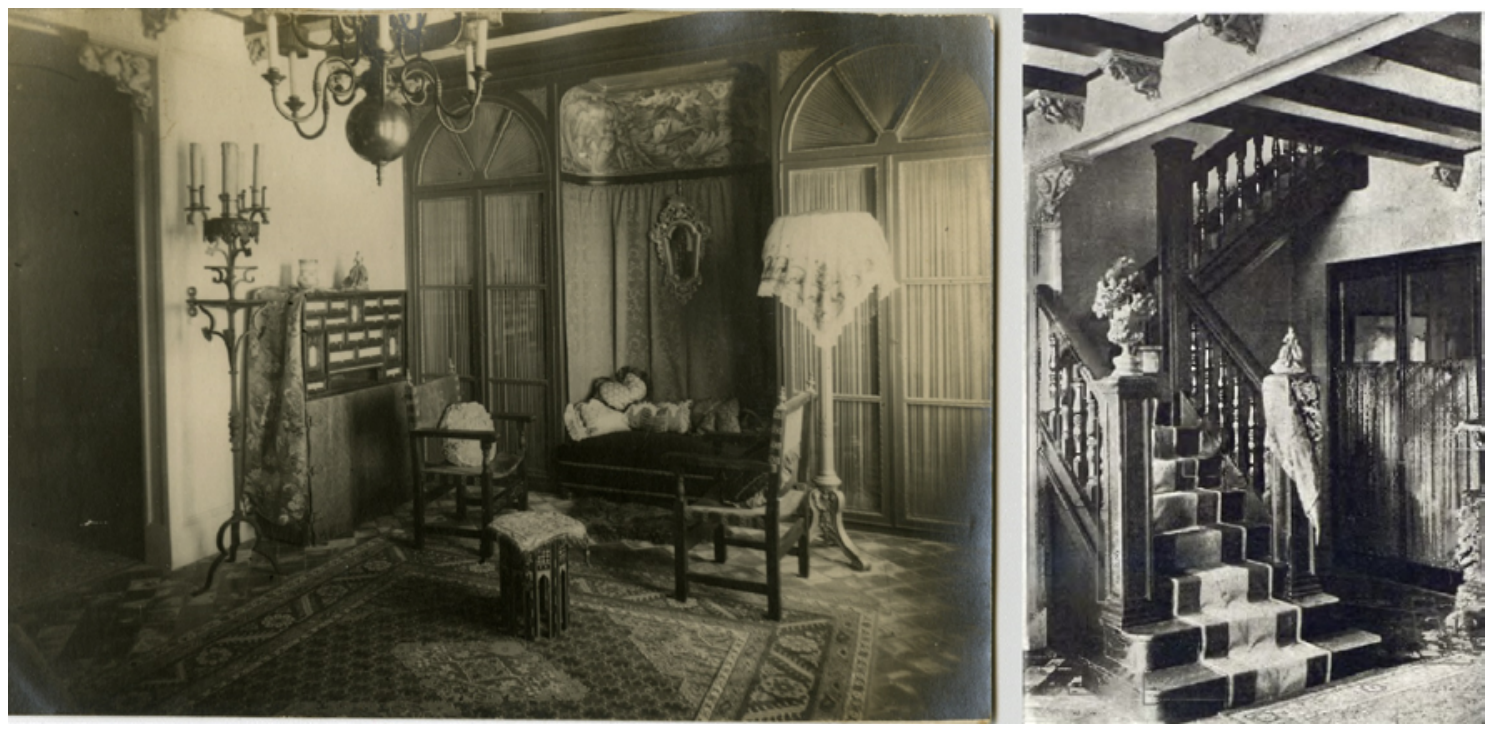

Fig.4: La Casa de Santiago Marco en 1920. Izquierda: Detalle de la sala de estar (FADA0229-32798C). Derecha: Escalera interior estudio artista. Anuari FAD 1920.

Podemos fechar la escalera en el año 1920. En el plano observamos como el tamaño es diferente; la de Puig i Cadafalch tenía un primer gran escalón y era mucho más larga, hasta el punto que arranca pasada la columna que sostiene los arcos. La de Santiago Marco en cambio arranca una vez pasada la columna, siendo más corta y con una inclinación más pronunciada. Observando intervenciones historicistas de Marco, constatamos como en todos los proyectos en que hay una escalera de madera, ésta es muy similar a la que podemos encontrar aquí. El gran pilar de madera que sostiene la escalera se decora con un capitel ajedrezado con relieves redondeados ${ }^{15}$, mientras el pie y los pilares que unen las barandas se rematan con elementos vegetales.

En la fotografía se aprecia que del cuerpo de la escalera cuelga una gran cortina, un brocado con un escudo bordado, donde se ve un castillo y un árbol. El escudo heráldico parece ser el de la familia Catarineu; y es que, aunque se la conociese como la "Viuda de Rosal", María Dolores Catarineu no renunció a sus orígenes familiares. En este sentido, la representación heráldica de la escalera y los vitrales ponen de relieve la aspiración de la burguesía industrial a ennoblecer y prestigiar su linaje.

\subsection{Laboratori de Tècnica Policial de la Generalitat de Catalunya (1936-1939)}

Para saber cómo era el comedor y la sala de la casa Rosal debemos trasladarnos a la guerra civil española. En este momento la vivienda está expropiada 
por la Generalitat de Catalunya para las dependencias del Laboratori de Tècnica Policial, supervisado por la Comissaria General d'Ordre Públic. El edificio acogía diversas instalaciones, entre ellas, un museo criminológico, una biblioteca y una sala de armas.

En 1937 se editó una publicación propagandística de las tareas del laboratorio y hay algunas fotografías de su interior. Lo que se aprecia, es que en esta época se redistribuyó la decoración de les espacios proyectados por Santiago Marco, por ejemplo, en el vestíbulo (fig.5). Se pueden ver objetos que ya había antes como la arquimesa, los sofás que aparecen retapizados y algunas de las lámparas. Los otros elementos que son ajenos a la decoración de 1921-aparte de las armas - posiblemente ya estaban en la casa, pero situados en otras estancias.
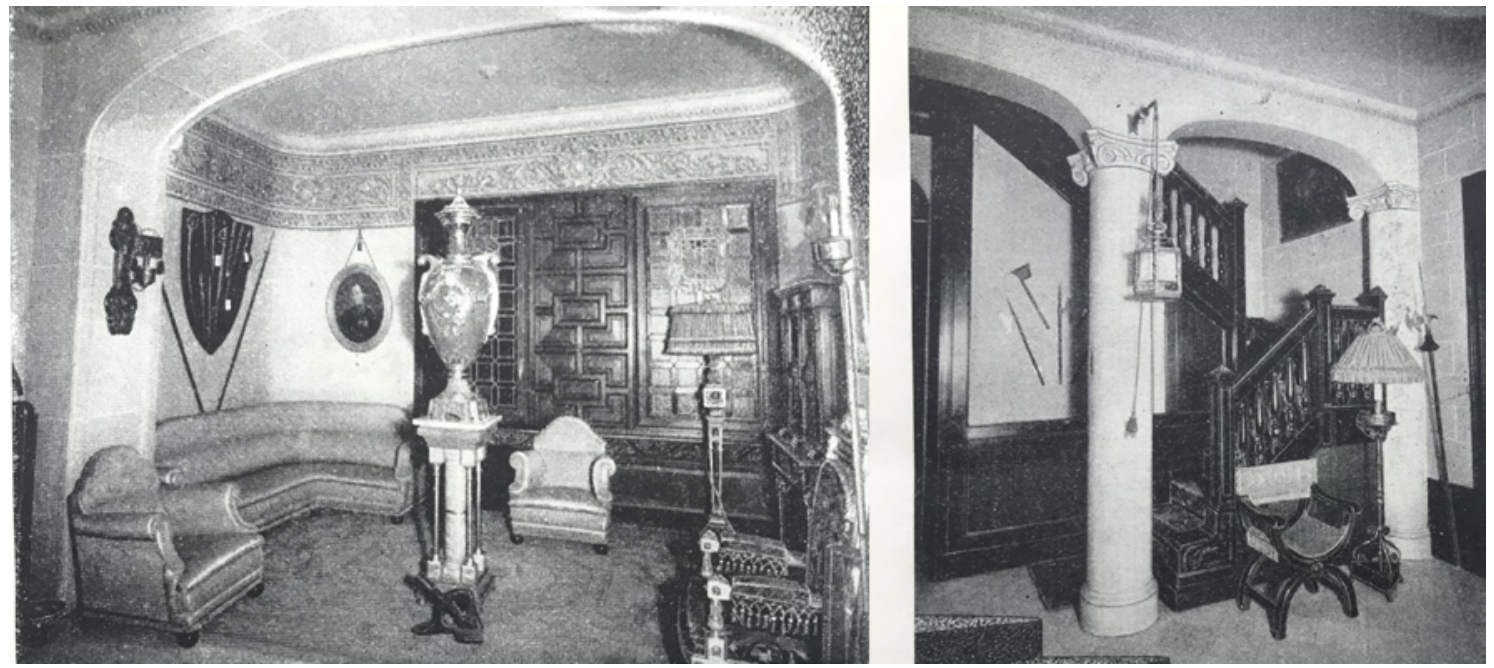

Fig.5: Vestíbulo en 1937. Laboratori de Tècnica Policial. Comissaria General d’Ordre Públic. Generalitat de Catalunya, 1937.

\subsubsection{Sala}

El museo de armas del laboratorio estaba situado en lo que seguramente era la sala, cumpliendo el mismo propósito para el cual fue concebida por Puig i Cadafalch. En la reforma de 1920 se unificaron las dos salas contiguas (fig.2, 2.1) para crear un espacio de grandes dimensiones de estilo Luis XIV (fig.2, 2.2). Tanto en la fotografía como en el plano se observa una pareja de columnas al final de la sala, típicas de las interpretaciones de este estilo.

Todas las paredes de la estancia estaban cubiertas por un damasco con decoración tipo cachemira, como se desprende de fotografías de detalle de la sala. En la parte superior se colocó un friso clásico de triglifos y metopas con mútulos y una cornisa de ménsulas que sostiene un relieve de gran calidad. La decoración parietal aún se conserva hoy en día más o menos íntegra.

La decoración y la concepción del espacio es parecida a otro proyecto de Marco sobre un salón de estilo Luis XIV para la casa de D.P.B y L. que aparece ilustrando el anuario del FAD de $1921^{16}$.

No hay que olvidar que pocos años antes, entre 1917 y 1919, Marco había recibido el encargo de decorar el Hotel Ritz de Barcelona ${ }^{17}$ en estilo Luis XVI; 
puede ser que las soluciones espaciales allí adoptadas se hubiesen repetido en estas estancias, en sintonía con la estética de los luises.

\subsubsection{Sala dels miralls o el laboratorio dáctilo-antropométrico}

El laboratorio dáctilo-antropométrico ocupaba lo que actualmente se llama la Sala dels miralls, ya que un gran espejo preside la estancia. Por lo que se observa en la fotografía de 1937 (fig.6), la decoración parietal actual ya existía. Es, por lo tanto, una decoración original de la ampliación de 1920, en estilo Luis XIV, acorde con la sala.

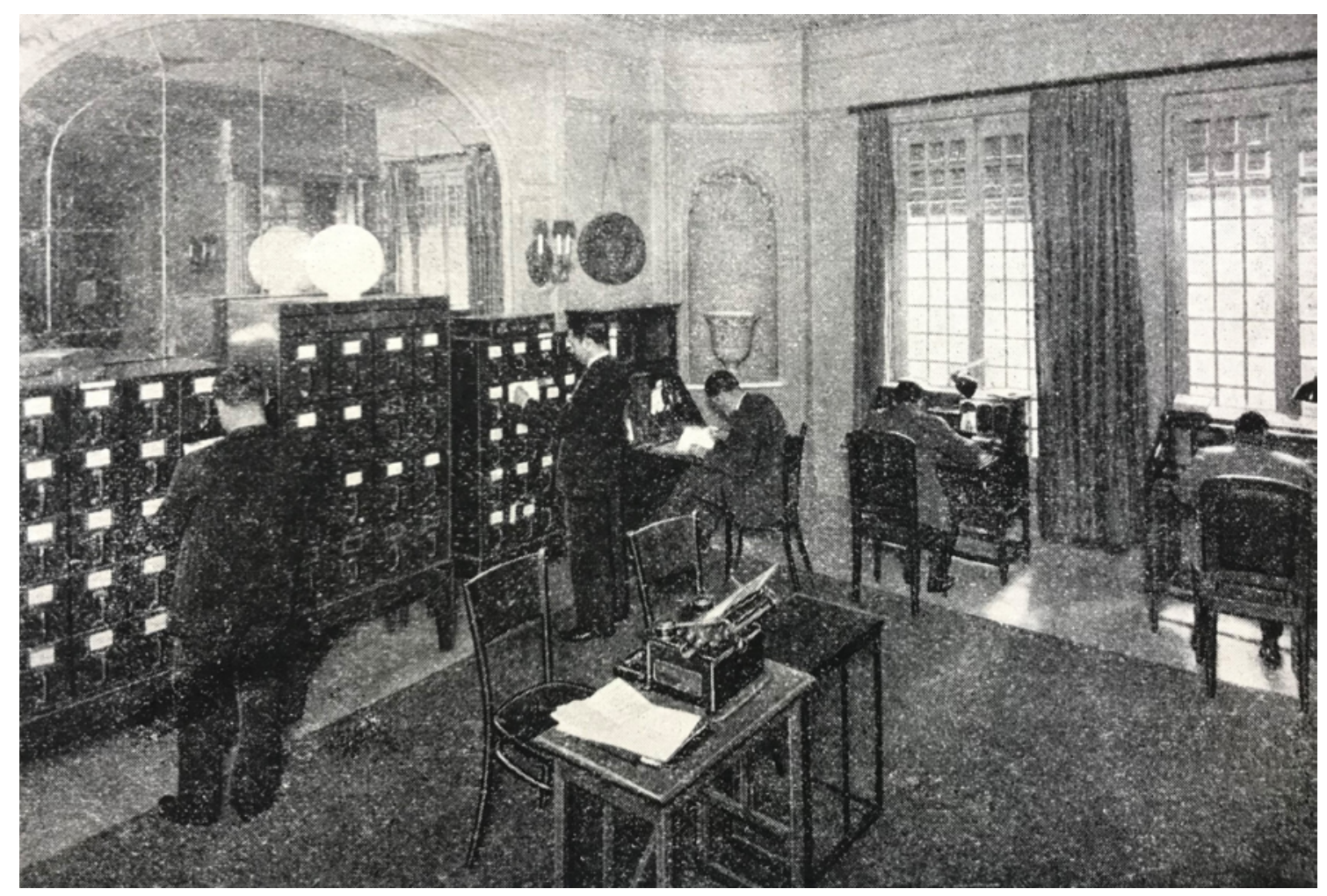

Fig.6: Laboratorio dáctilo-antroponométrico en 1937. Laboratori de Tècnica Policial. Comissaria General d’Ordre Públic. Generalitat de Catalunya, 1937.

Para entrar en la estancia se accede por una gran puerta en forma de arco de medio punto, flanqueada por dos columnas estriadas exentas, rematas por un capitel jónico moderno. Estas columnas parecen tener una función estructural, pues sostienen un rebajo del techo que se integra en la habitación mediante una fina moldura. Al lado de cada columna, se abrió una pequeña puerta hacia estancias desconocidas. En la pared opuesta, de las mismas dimensiones que la puerta, se colocó un gran espejo realizado con piezas cuadradas, sostenidas por tornillos ocultos por apliques florales conservados aún a día de hoy. Este tipo de espejo era habitual en los años 20, sobre todo en comedores (fig.7), presidiendo la estancia y situando en paralelo a una mesa, aunque lo podemos encontrar igualmente en otras salas de representación ${ }^{18}$. El espejo queda encuadrado en la pared mediante pequeñas molduras geométricas, decoradas originalmente con 
marmoleado ${ }^{19}$. En las molduras redondas se colocaron dos apliques de bronce estilo neobarroco con tres brazos y pantalla de tela, flanqueando el espejo. Estas lámparas también han llegado a nuestros días y guardan relación con otros proyectos de Santiago Marco.

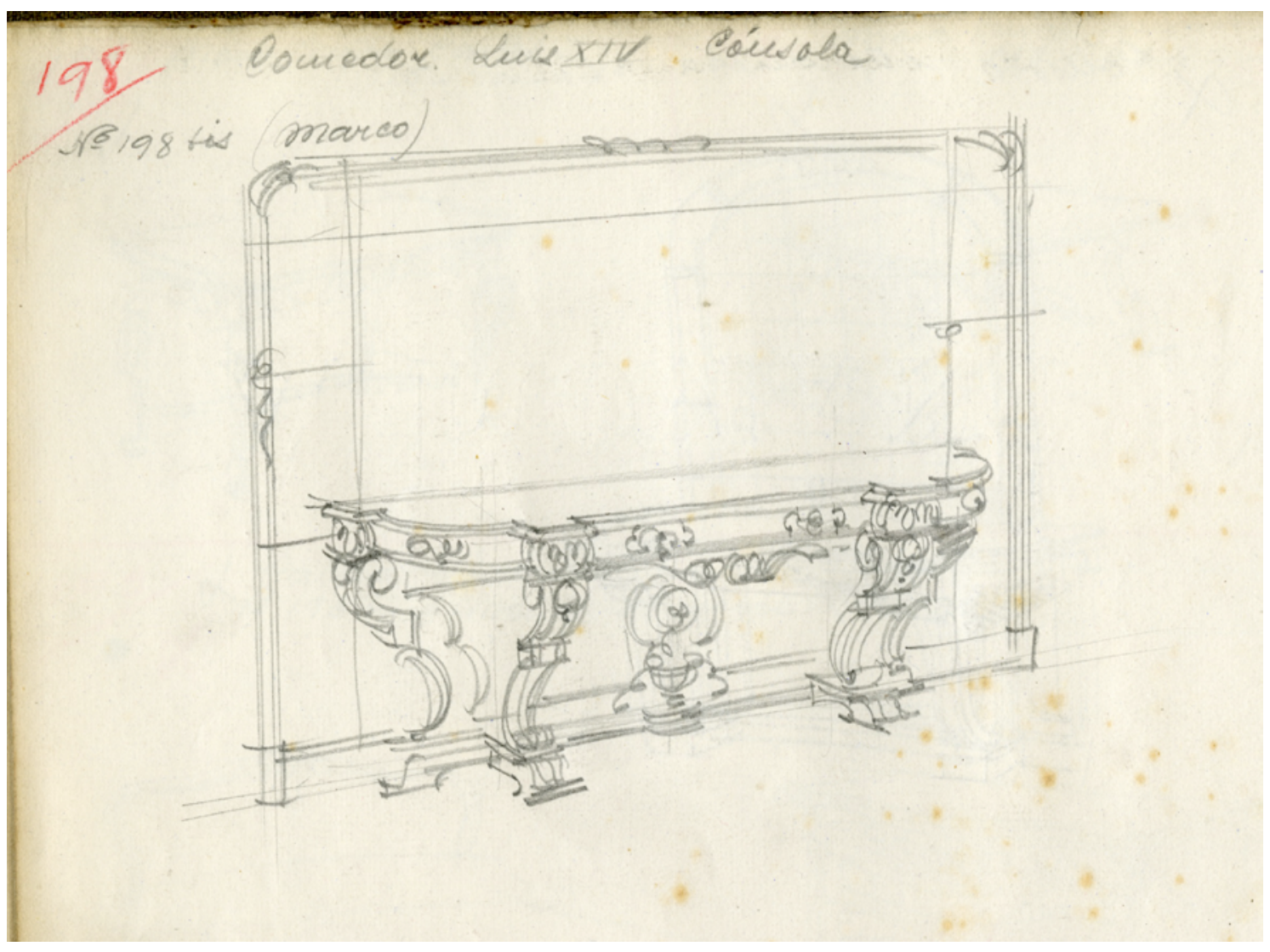

Fig.7: Consola con espejo para comedor de Pallerols. Entre paréntesis, "Marco", hace alusión a un encargo de nuestro decorador (A0032-05-198).

Las esquinas de esta pared se achaflanaron y se abrieron dos fornículas, también a los lados del espejo donde se dispusieron dos grandes jarrones, mientras que en las paredes se colgaron platos, posiblemente metálicos. En la fotografía del vestíbulo de 1920 (fig.4) se ve, a través del pasillo del comedor, esta misma decoración un gran ramo de flores en el jarrón del nicho y un plato metálico colgado en la pared.

Después de lo expuesto, parece razonable argumentar que Santiago Marco se responsabilizó del diseño íntegro del interior de la casa en la reforma de 1920 y no solamente del vestíbulo que tenemos fotografiado. La razón por la que se le encargó la decoración no la conocemos, pero la prensa nos podría sugerir una explicación.

El periódico La Vanguardia publicó la noticia que el día 16 de junio de 1936 al mediodía se celebró una boda en el oratorio del "chalet" entre Isabel Ventosa Despujol (1916-2001), hija del exministro Juan Ventosa Clavell (1879-1959), y Fernando Rosal Caterineu (1900-1970), hijo de María Dolores Caterineu. El enlace contó con la bendición del obispo de Barcelona y uno de 
los padrinos fue el político y empresario catalán, Francesc Cambó. El mismo Cambó que promovió la construcción del Hotel Ritz en Barcelona, la decoración del cual fue obra de Marco entre 1917 y 1919. Si bien Marco ya gozaba de buena reputación en aquel momento, Francesc Cambó podría haberlo recomendado a la familia Rosal.

Lo que se puede asegurar es que la relación de Santiago Marco con los Rosal continuó después de dicho encargo. Entre los proyectos que se encuentran en el archivo del artista, destaca el Living-room de otra viuda Rosal, Paulette Labarriere, que también asistió a la boda anteriormente citada. El interés de esta sala de estar reside en que se trata de la biblioteca que Marco hizo para la exposición del Pavelló dels Artistes Reunits a l'Exposició Internacional de Barcelona de $1929^{20}$. Si bien, por ejemplo, el dormitorio se destinó a la casa del Sr. Jaume Martí, la biblioteca se ubicó en la casa particular de Paulette Labarriere en la calle Muntaner.

2.4. La Clínica del Doctor Melcior Colet (1941-1981). Los arquitectos E. Matas y R. Homs y Santiago Marco

En 1940, una vez terminada la guerra civil, la propiedad volvió a manos de la familia Rosal. Poco después la vendieron al doctor Melcior Colet (18981984) que quería ubicar su clínica ginecológica en el edificio. En 1941 solicitó el permiso de obras al Ayuntamiento de Barcelona (exp.4.728) con un proyecto firmado por los arquitectos E. Matas y R. Homs. El proyecto supuso un cambio radical: se construyeron nuevos cuerpos en el edificio y se incorporó un ascensor y un montacargas ${ }^{21}$ si bien se conservaron los pavimentos de la reforma de 1920; a Santiago Marco se le encargó la decoración del interior de la clínica.

Entre la primera y segunda intervención en la Casa Company habían pasado poco más de 20 años. Entre tanto, Marco se había convertido en el decorador más importante e influyente de Catalunya. En 1923 asumió la presidencia del Foment de les Arts Decoratives con un programa de desarrollo noucentista ${ }^{22}$ de la entidad y además obteniendo ese mismo año el Gran Premio en la Exposición Internacional del Mueble y Decoración de Interiores de Barcelona con su Salón de té. Allí, auspiciado por Joaquim Folch i Torres, se criticaba la presencia del mueble extranjero y se propugnaba la búsqueda de personalidad en muebles e interiores enlazándola con la propia tradición ${ }^{23}$. En la exposición de Paris de 1925 ganó una medalla de oro con el Bodoir Améthyse con la intención de que se podía mostrar al mundo que, en España, y más concretamente en Catalunya, representada por el FAD, había interiores modernos a pesar de la multitud de casas decoradas con estilo neorenacimiento y neoplateresco ${ }^{24}$. En este sentido, tal y como indica Fondevila en el Anuari del FAD de 1926, Marco escribe: El tradicionalisme ensopeix l'art a casa nostra i li priva de fer el tomb decisiu que per tot arreu del món está provant, amb més o menys encert $i$ inspiracióo ${ }^{25}$.

Aun así, había clientes que le encargaban interiores historicistas, pero según Folch i Torres todas las obras de Marco se caracterizaban por la ponderación: Ponderació. (...) Les obres per ell dirigides en duen totes la marca inconfundible (...) tant si interpreta els estils històrics, com si crea obres de la més aguda modernitat, és el d'una delicada i assenyada ordenació de les coses ${ }^{26}$. 
En los años siguientes a través del FAD llevó a cabo otras exposiciones importantes que marcarían toda una generación de artistas. Conviene destacar el Pavelló d'Artistes Reunits para la Exposición Internacional de Barcelona de 1929 y el I Saló d'Artistes Decoradors de 1936. Entre esos años, Marco llevó a cabo proyectos importantes, como la decoración del Tribunal de Cassació de Catalunya y el Parlament de Catalunya (1933). Era el decorador de referencia.

La Guerra Civil Española supuso un punto de inflexión en su carrera. Parece $\operatorname{ser}^{27}$ que, una vez terminada fue citado por el juez de responsabilidades políticas, ya que Marco había ostentado la presidencia del FAD durante los años anteriores a la guerra civil, pero fue absuelto. De hecho, Marco había participado en 1938 en la dirección de la Exposición Internacional de Arte Sacro de Vitoria, organizada por el primer gobierno franquista ${ }^{28}$, por lo que su posible vinculación con el gobierno anterior quedaba redimida.

A partir de entonces se truncó la renovación y la búsqueda de nuevas premisas. Sus proyectos volvieron al historicismo de los primeros años y a formulas y recursos recurrentes que le habían funcionado anteriormente. Abrazó antiguos valores sociales y culturales en los que la arquitectura y el interiorismo moderno y racionalista no tenían cabida, contraponiendo, así, el II Salón de Artistas Decoradores de 1942 al que había realizado en 1936. La evolución del diseño en España se había detenido ${ }^{29}$.

De la intervención de Marco en Casa Company en el año 1942 se han conservado cuatro fotografías del despacho del doctor Colet. Se desprende, entre otras evidencias, que el historicismo había entrado en todos los rincones de la casa. De este modo, Marco había cerrado una etapa y abría otra que contrastaba mucho con las clínicas racionalistas del doctor Ferrando y del doctor Montroset, que había realizado a principios de los años $30^{30}$.

\subsubsection{Vestíbulo}

No hay información de cómo era la decoración del vestíbulo en esta nueva etapa, pero se observan cambios estructurales importantes. Tal y como se ve a día de hoy, la columna y los arcos que presidian la escalera se eliminaron en esta fecha (la columna aparece marcada en amarillo en el plano del proyecto (fig.2, 1.2), señal de que se debía suprimir). En su lugar, se colocó una gran viga con dos cartelas de yeso que simulan sostenerla, situando otras más pequeñas en el pasillo y en la planta superior.

Esta idea no era nueva. En 1920, Marco ya había utilizado este mismo recurso en la escalera de su casa particular con considerable éxito ${ }^{31}$ (fig.8). Las figuras de yeso son las mismas en ambos casos y utilizadas de igual manera: una más grande para la jácena y otras más pequeñas para las vigas. Representan criaturas y animales antropomorfos mezclados con volutas y escudos, que recuerdan a los grutescos de inspiración renacentista. 


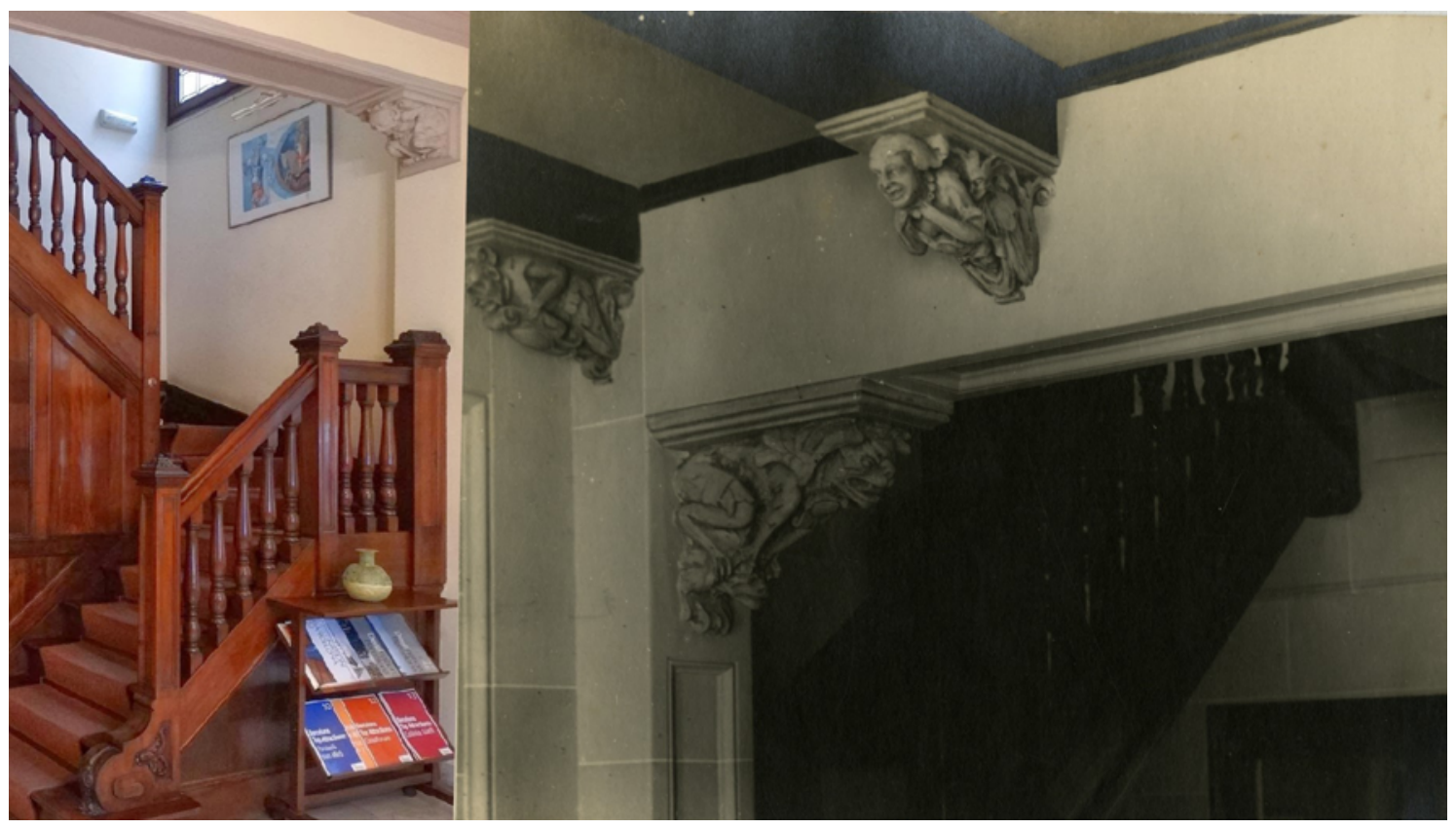

Fig.8: Izquierda: Imagen actual del vestíbulo. Derecha: Detalle del techo del vestíbulo de la casa de Santiago Marco en 1920 (FAD-A0229-32805C).

\subsubsection{Sala}

Si consultamos el plano de obras, el espacio que albergaba el museo de armas, es decir la antigua sala de la familia Rosal, parece no albergar cambios en esta intervención. Aun así, seguramente sí se produjeron, pero por motivos desconocidos no quedaron reflejados en los planos del proyecto. Al parecer, se levantó una pared donde estaban las dos columnas y se abrió un acceso a la nueva sala desde el hall. Además, las puertas de acceso y salida de estos espacios se decoraron con pilastras jónicas al estilo de la sala tal y como pueden verse en la actualidad.

\subsubsection{Pasillo curvo}

El comedor de la casa quedó dividido en 1942 por un pasillo curvado que se puede observar en el plano de Matas y Homs (fig.2, 4.2). Se realizó para comunicar la sala de espera y el despecho del doctor, al mismo tiempo que permitía ubicar, detrás de las paredes del mismo, las salas de la enfermería. Este pasillo se eliminó en 1983 durante la restauración de la casa por parte de Joan Bassegoda i Nonell.

El corredor estaba iluminado por una cristalera con motivos grabados que se abría al jardín. Ha llegado hasta nuestros días, aunque situada en la caja helicoidal de la escalera de la casa. En el fondo de archivo de la reconocida empresa de vidrieras artísticas Rigalt que se conserva en el Museu del Disseny, aparece $^{32}$ una referencia que podría responder al encargo para elaborar dicha pieza, ya que encaja con la descripción, el encargo y la cronología: "36 - Dtr. Colet - Dec. Santiago Marco - grabados, 1942"33 


\subsubsection{Sala dels miralls o el despacho del doctor Colet}

El despacho del doctor Colet se ubicaba en la actual Sala dels miralls, el mismo sitio que había ocupado el laboratorio dáctilo-antropométrico el 1936. Es el espacio más representativo de la intervención de Santiago Marco al conservarse más o menos íntegro y además por estar documentado con fotografías de la época ${ }^{34}$ (fig.9). En esta estancia Santiago Marco no tocó prácticamente nada de la estructura original de 1920. Es más, reaprovechó el antiguo espejo y los apliques de pared para integrarlos a un nuevo interiorismo. De esto se desprende, que el doctor Colet adquirió la casa con parte del mobiliario que había quedado del chalet de los Rosal y posiblemente del Laboratori de Tècnica Policial. De hecho, el 24 junio de 1987 se llevó a cabo la subasta de arte del doctor Melcior Colet y se vendió un jarrón sobre columna por 550.000 pesetas que bien puede tratarse del que se ve en la fotografía del vestíbulo del año 1937 (fig.5) y que habría pertenecido a la familia Rosal.
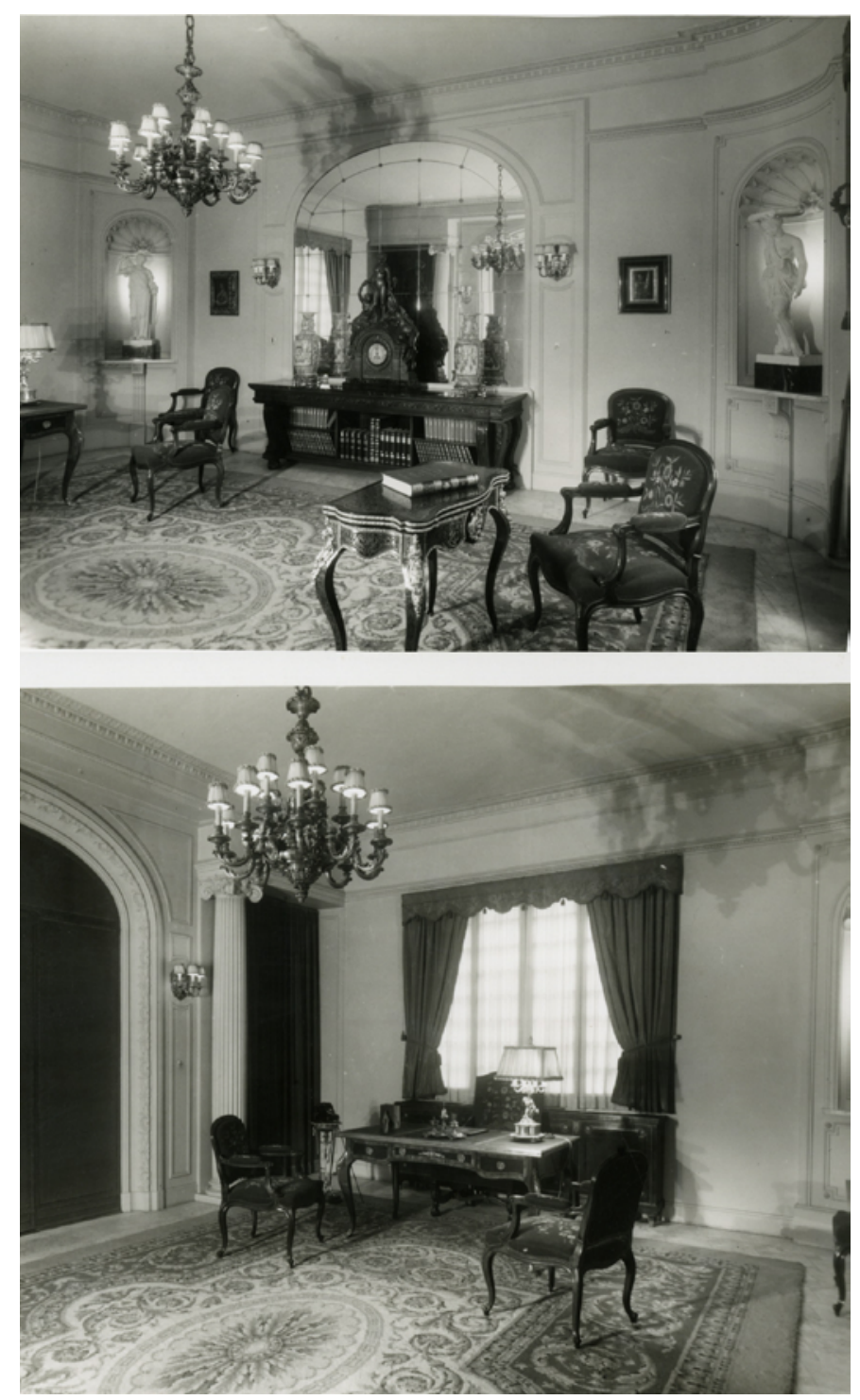

Fig.9: El despacho del Dr. Colet. Arriba (FAD-FT001254-A-I). Abajo (FAD-FT0012-54-A-S). 
Nos puede extrañar el reaprovechamiento de elementos ya existentes, pero lo más seguro es que Marco consideró que estas piezas se acomodaban a las características que debía tener la nueva sala: lujosa y al estilo Luís XV.

Las ventanas y las puertas secundarias de los lados se cubrieron con cortinas unificando los planos de pared, mientras que el suelo se cubrió con una alfombra de lana de grandes dimensiones con motivos renacentistas.

Distribuidas por la estancia, había seis butacas de brazos de estilo Luis $\mathrm{XV}$, de roble ebonizado, tapizadas de terciopelo con bordado floral, aunque actualmente retapizadas con terciopelo rojo. Un bureau plat con tres cajones preside el despacho desde un lateral, de estilo Luis XV y de caoba, roble y maderas exóticas, con tiradores, bocallaves, escudetes y pies en forma de pata de león en bronce dorado. El sobre está forrado de piel y embellecido con guadameciles dorados. Se observa que ha sido restaurado hace pocos años.

Para sentarse en la mesa de despacho, Marco colocó un sillón o fauteuil Luís XIV de roble con chambrana en forma de $\mathrm{H}$, las patas frontales se embellecieron con unas cariátides y se tapizaron a juego con las butacas de brazos. Cabe destacar que es el único mueble que no es de estilo Luis XV, sino que es Luis XIV. Tradicionalmente, el estilo Luis XV es considerado como femenino, mientras que el XIV representa la masculinidad y la autoridad; el fauteuil Luís XIV era concebido en su momento un mueble ceremonial y representativo de la rígida jerarquía de la aristocracia francesa. Situar una pieza con tal carga simbólica en un despacho de una clínica ginecológica buscaba transmitir autoridad tanto desde un punto de vista profesional como de género.

Encontramos también dos muebles bajos. Uno se colocaba debajo del espejo y servía para guardar libros en sus múltiples estantes. Las patas son de garra y bola, mientras que los laterales y frontales de los montantes se decoran con ménsulas estriadas con volutas y hojas de acanto. El frontis se decora con una cenefa corrida de tipo candelieri mientras que el sobre es de mármol negro. El otro mueble bajo es una tapa de radiador de grandes dimensiones, embellecido por tres casetones, el central de grandes dimensiones, que se decoran con cestos de flores en bronce dorado.

Otras piezas de la estancia, hoy desaparecidas, eran una mesa auxiliar estilo Luis XV con decoración Boulle, un reloj de bronce con figuras alegóricas firmado como J. Bonnassieu $1884^{35}$, un trípode Luis XV con teléfono, una estantería modular con una gran figura de bronce de un ángel victorioso sosteniendo un laurel ${ }^{36}$, una pareja de pinturas y dos jarrones de porcelana de Dresden ${ }^{37}$.

El estudio de las piezas conservadas permite afirmar que el conjunto del despacho se realizó en taller de Joaquim Campanyà, colaborador habitual y amigo $^{38}$ de Santiago Marco. El taller estaba situado en la calle Còrsega 561 de Barcelona.

Entre la documentación conservada del mencionado taller en el Centre de Documentació del Museu del Disseny hay dos bocetos ${ }^{39}$ del bureau plat Luis XV del despacho de Colet, que se corresponde al modelo 1797 y al lado la referencia con los diferentes despachos a los que iba destinado este modelo. A parte del doctor Melcior Colet, también se subministró a los despachos de Manuel Viladomiu, José Gaspá y Salvador Marsal ${ }^{40}(f i g .10)$. 


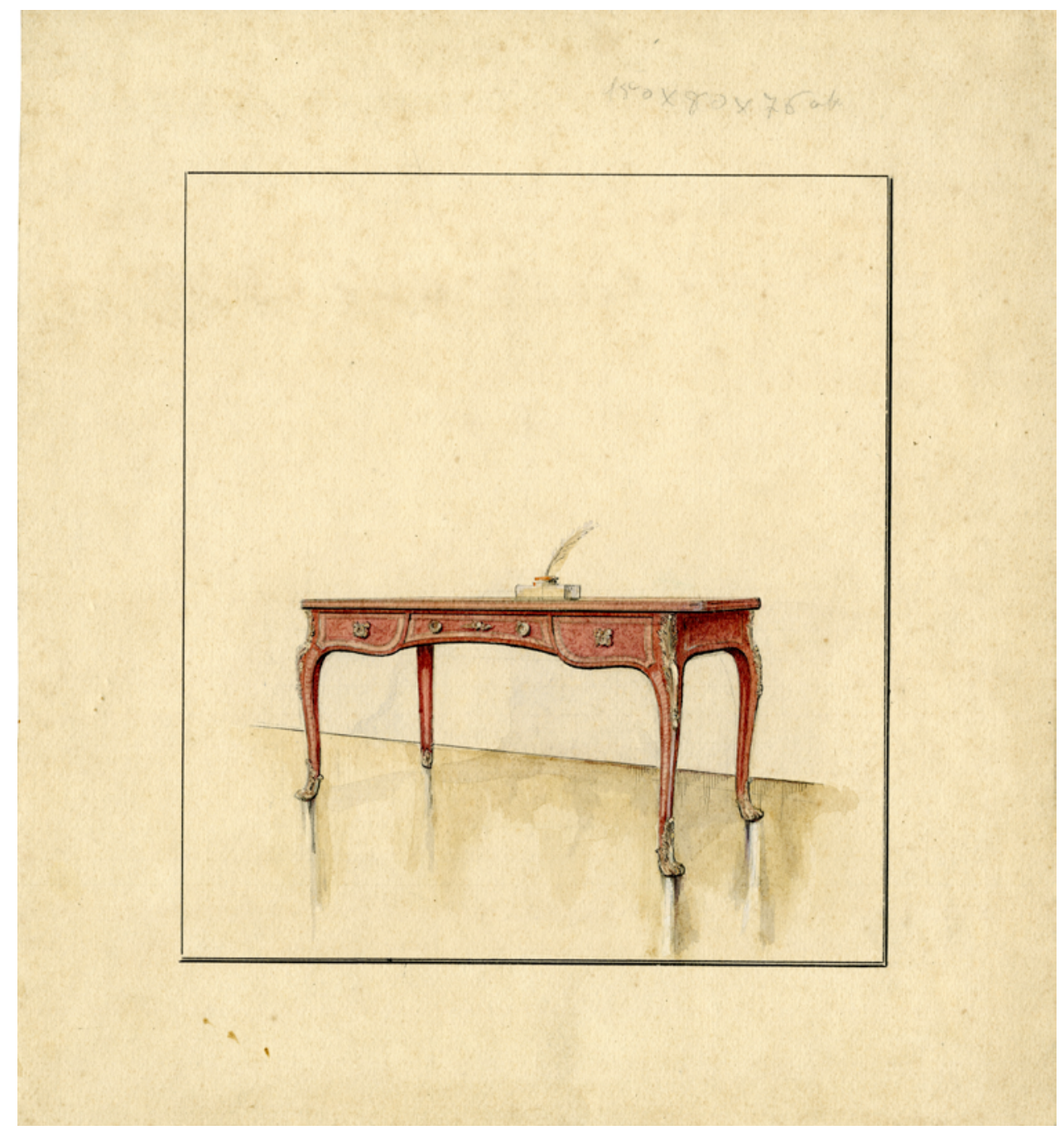

Fig.10: Boceto de la mesa de despacho (CAM-AL0001-13_002).

No se ha encontrado el modelo exacto de las sillas y el fauteuil entre la documentación de Campanyà, pero sí de otros muy similares, con pequeñas variaciones dentro de unos mismos modelos de luises. La estrecha relación de amistad y colaboración laboral entre Marco, Campanyà y Perfecte Llosà, hace pensar que las tapicerías de los muebles del despacho podrían haber sido elaboradas por este tapicero, miembro también del FAD con una tienda en la calle Balmes, 128.

Encontramos el mismo modelo de sillas en otro proyecto de Santiago Marco: la sala de estar de la Casa de Salvador Catà que podríamos fechar en la década de 1920 (fig.11). Allí, la distribución de los diferentes objetos y muebles es muy parecida a la del despacho del doctor Colet. También se sitúa una mesa de trabajo a un lado y el centro de la estancia está ocupado por una mesa pequeña - en el caso del despacho sería la mesa Boulle - con dos sillas, para conversar de una manera más informal. Un espejo de grandes dimensiones preside la sala y debajo un mueble que sirve de repisa para una escultura de bronce y dos jarrones de porcelana; en los laterales, dos apliques de pared.

Por último, cabe destacar las esculturas de yeso situadas en las hornacinas del despacho. Una representa a la diosa Afrodita, concretamente es una 
copia de la pieza griega de Kallimachos del 400 ac., mientras que la otra es una copia de la amazona de Carlo Albacini c.1780. Por la parte de atrás, estas piezas tenían una lámpara para crear iluminación ambiental, aunque en la restauración de las piezas llevada a cabo en 2017 se eliminó esa función.

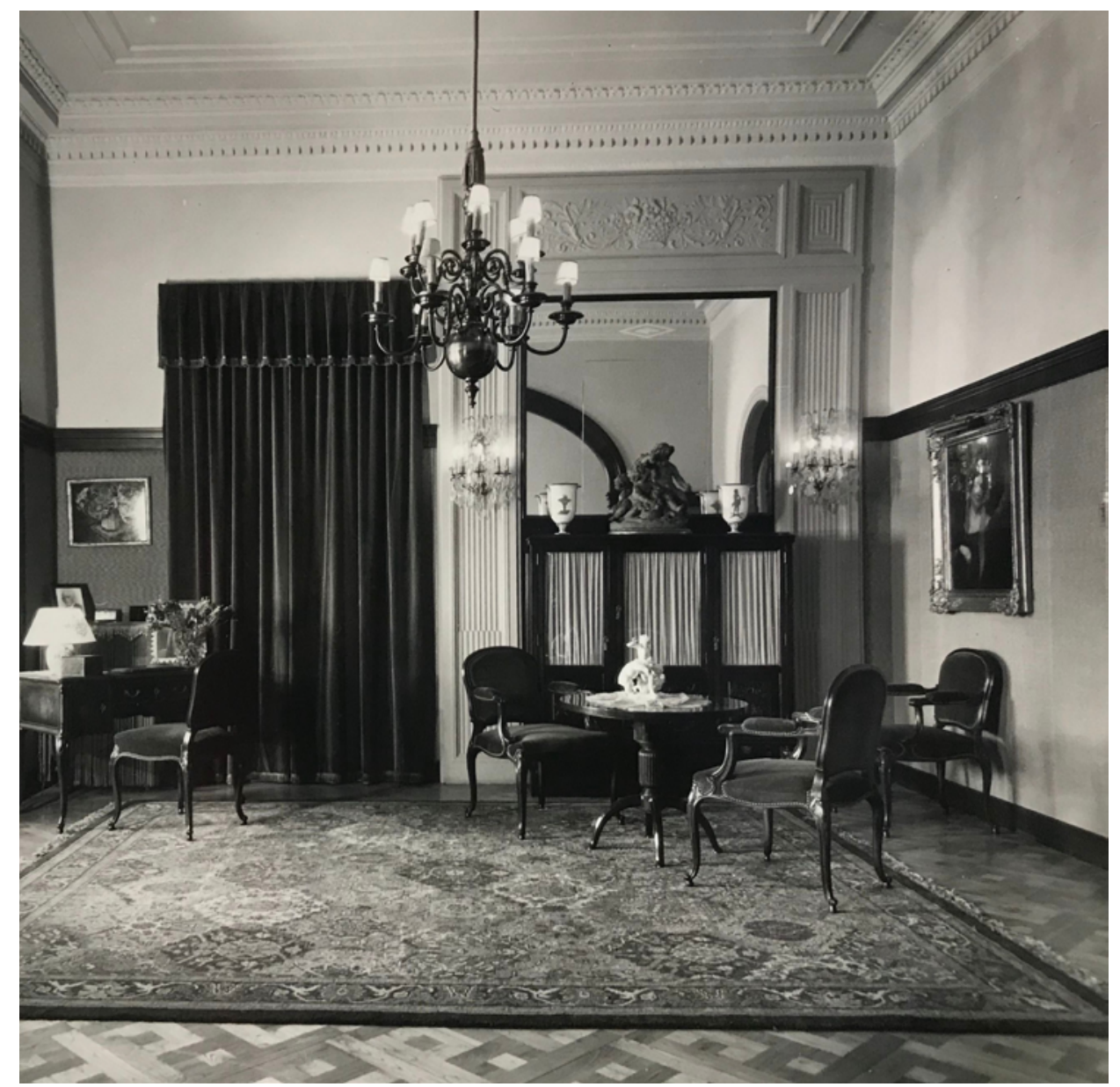

Fig.11: Sala de estar de Casa Salvador Catà, sobre 1920 (FAD A0195, carpeta 4).

La primera aparición de la escultura de la amazona es de 1941 en el $I I$ Salón de Artistas Decoradores, organizado por el FAD en la Cúpula del Coliseum de Barcelona. El Salón se dedicó a la infancia y esta pieza decoraba el estand número 14, un cuarto de baño presentado por S.A. Verdaguer (fig.12). En el estand participaron numerosas empresas, como los cristales de la mano de Granell y Cía., los mosaicos de Escofet, la pintura de Vilaró y Valls S.A. etc., pero en la documentación conservada no se menciona la autoría de las esculturas.

Santiago Marco no participó con un estand propio, pero conociendo su personalidad, seguramente colaboraba en todos los proyectos para que la exposición fuera un éxito. Marco sí que participó en la primera edición del Salón de 1936 en el estand número 2: un baño, presidido por un gran bajorrelieve de Afrodita realizado por el escultor C. Collet. Es posible que tomara esa misma idea para el Salón de 1941. Al terminar el II Salón la escultura se colocó en la Clínica del doctor Colet. No parece que la pieza de Afrodita estuviera en la 
exposición; se creó exprofeso para el despacho. Estas esculturas con función de lámparas tienen su evolución lógica dentro de la trayectoria artística de Marco, pues en años anteriores ya había llevado a cabo los jarrones-lámpara que en tantos proyectos de Marco podemos encontrar, por ejemplo, en el edificio del Parlament de Catalunya, situado en el Parc de la Ciutadella en Barcelona.

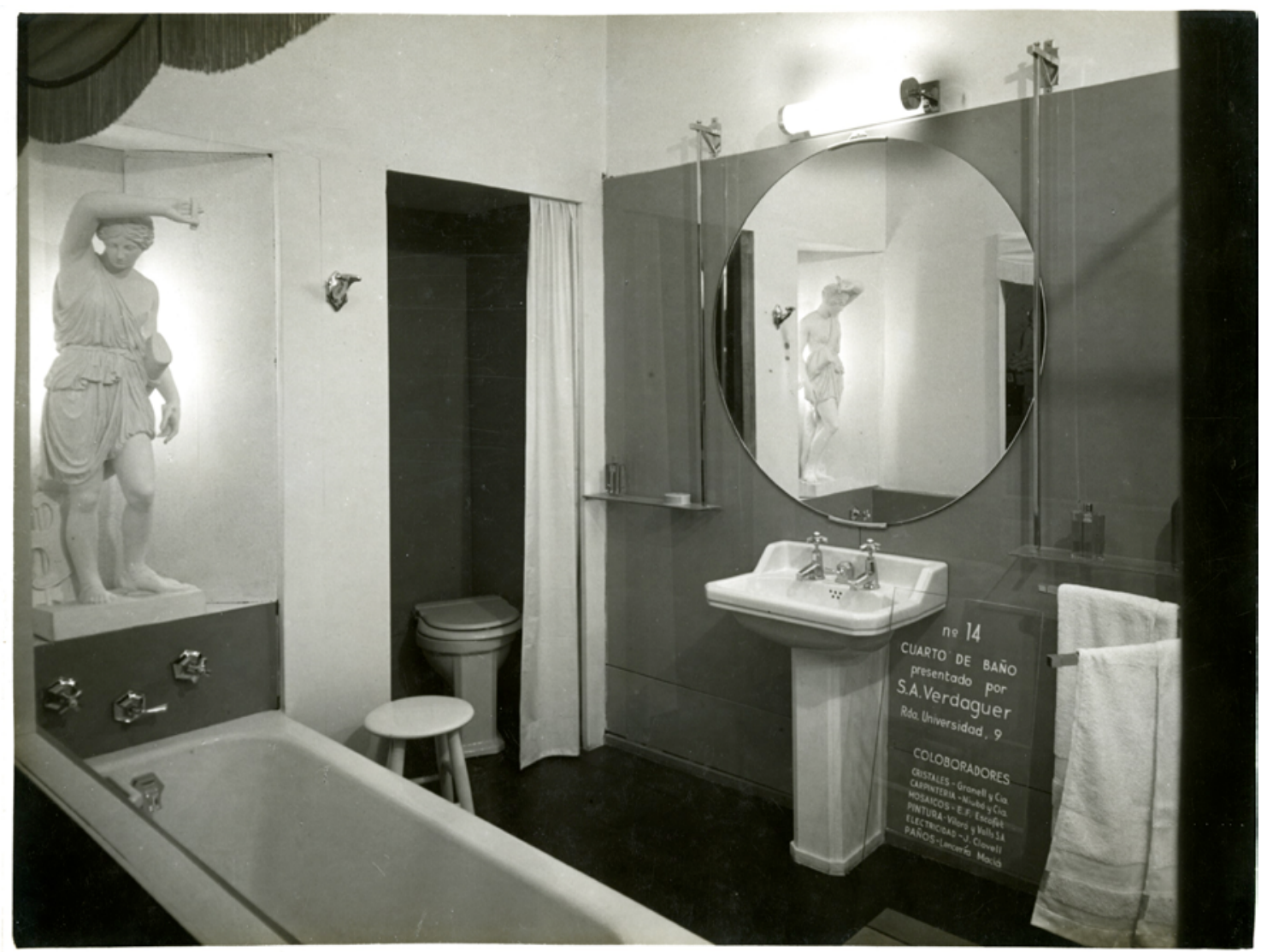

Fig.12: Estand núm.14 del II Salón de Artistas Decoradores (FAD-A0037-14_001).

\section{NOTAS}

1 La Veu de Catalunya: diari catalá d'avisos, noticias y anuncis, any $32, \mathrm{n}^{\circ} 8248$, ed. del matí (31-8-1922): 2, Arxiu de Revistes Catalanes Antigues (ARCA), https://arca.bnc.cat/arcabib pro/ ca/catalogo imagenes/grupo.do?path $=1255959$

${ }^{2}$ Los Deportes: revista española ilustrada de automovilismo, ciclismo, aviación y demás deportes, turismo, educación física, etc., año 07, nº 051 (20-12-1903): 819. Arxiu de Revistes Catalanes Antigues (ARCA), https://arca.bnc.cat/arcabib pro/ca/catalogo imagenes/grupo. do?path $=1023793$

${ }^{3}$ La Veu de Catalunya: diari catalá d'avisos, noticias y anuncis, any $13, \mathrm{n}^{\circ} 1565$, ed. del vespre (30-5-1903): 4, Arxiu de Revistes Catalanes Antigues (ARCA), https://arca.bnc.cat/arcabib pro/ ca/catalogo imagenes/grupo.do?path $=1230567$

${ }^{4}$ La Veu de Catalunya: diari catalá d'avisos, noticias y anuncis, any $20, \mathrm{n}^{\circ} 3978$, ed. del vespre (1-6-1910): 4, Arxiu de Revistes Catalanes Antigues (ARCA), https://arca.bnc.cat/arcabib pro/ ca/catalogo_imagenes/grupo.do?path $=1239987$ 
${ }^{5}$ Por la información consultada en esta misma entidad, fue socio del Ateneu Barcelonès entre 1886 y 1914.

${ }^{6}$ La Veu de Catalunya: diari catalá d'avisos, noticias y anuncis, any17, $\mathrm{n}^{\circ} 2942$, ed. del vespre (2-7-1907): 4, Arxiu de Revistes Catalanes Antigues (ARCA), https://arca.bnc.cat/arcabib pro/ ca/catalogo imagenes/grupo.do?path $=1236083$

${ }^{7}$ En el Ateneu Barcelonès, Pere Company hacía constar su vivienda habitual en la calle Bruc y más tarde en la calle Princesa. Nunca apareció la casa de la calle Buenos Aires, por lo que se supone que era una segunda residencia.

${ }^{8}$ La Vanguardia. Diario Independiente de Barcelona, año 41, nº 18.254, ed. Mañana, (23-71922): 18.

${ }^{9}$ Ines Dal Maschio Eisele y Josep Padró Margó, La Colonia Bros de Martorell. Un nucli manufacturer $i$ industrial (Materials del Baix Llobregat $\mathrm{n}^{\circ}$ 4, Centre d'Estudis Comarcals del Baix Llobregat, 1998): 119. https://dialnet.unirioja.es/servlet/articulo?codigo $=7157240$

${ }^{10}$ Dona i artista. La col lecció del Museu de Terrassa, (Ajuntament de Terrassa, Regidoria de Cultura, Museu de Terrassa, 2019):160 y 162.

${ }^{11}$ Dal Maschio y Padró, La Colonia Bros de Martorell, 119.

${ }^{12}$ Josep Camprubí i Plans, "Colònies tèxtils: una vitalitat que desapareix," Erol, La revista cultural del Berguedà, $\mathrm{n}^{\circ} 47$ (1995): 32-37.

${ }^{13}$ Se conserva en el Centre de Documentació del Museu del Disseny de Barcelona con fotos del Arxiu Mas del Instituto Amatller de Arte Hispánico.

${ }^{14}$ Joaquim Folch i Torres, Santiago Marco. 31 realitzacions (Barcelona: Quatre Coses, 1926): 13.

${ }^{15}$ El capitel, con esa curiosa decoración, parece ser original de 1911, pues en la chimenea modernista encontramos este mismo motivo decorativo, alejado del historicismo que proyectó Marco en 1920.

${ }^{16}$ Annuari del Foment de les Arts Decoratives (Barcelona: el Foment, 1921): 64. https://ddd.uab. cat/pub/fomartdec/fomartdec a1921v3.pdf

${ }^{17}$ Mariàngels Fondevila, Art déco català (1909-1936) (Barcelona: Universitat Autònoma de Barcelona, Publicacions i Edicions de la Universitat de Barcelona, Universitat de Girona, Edicions i Publicacions de la Universitat de Lleida, Edicions Universitat Politècnica de Catalunya, Publicacions de la Universitat Rovira i Virgili, i Museu Nacional d'Art de Catalunya, 2015): 202.

${ }^{18}$ Annuari del Foment de les Arts Decoratives (Barcelona: el Foment, 1921): 68.

${ }^{19}$ Con la retirada actual de las lámparas de pared se puede observar rastros del marmoleado original ya que se pintaron las paredes sin sacar las lámparas.

${ }^{20}$ La biblioteca encabezó un elogioso artículo de Josep Mainar en la revista d'Ací i d'Allà, $\mathrm{n}^{0} 159$ marzo 1931.

${ }^{21} \mathrm{El}$ detalle de esta obra se puede encontrar en: "1940-1983. Dr. Melcior Colet; reforma per transformació en clínica. Arquitectes Matas-Oms i decoració de Santiago Marco," Projecte Bàsic i Executiu de rehabilitació del Museu de l'Esport Dr. Melcior Colet Casa Company. Estudi Històric. (INCASOL, 2015).

${ }^{22}$ Indudablemente, el pensamiento noucentista impregnaba la sociedad catalana del momento, la estética era un medio para una ética. El ideario era profundamente estoico y alejado del mundo bohemio, buscaba los valores de la cultura, la civilidad, la mediterraneidad, el clasicismo, pero también daba importancia al concepto de l'obra ben feta, el trabajo como redención espiritual. Marco aplicó este pensamiento en el FAD con gran éxito. El art decó en Catalunya se mezcló con el pensamiento noucentista.

${ }^{23}$ Rossend Casanova Mandri, "Las lámparas de pie de Santiago Marco en la Exposición Internacional del Mueble de 1923," Art Déco. Història, materials i tècniques (Barcelona: Ajuntament de Barcelona, 2018):54. 
${ }^{24}$ Isabel Campi, "Art Decó en España. Estilo y cultura de masas," The Barcelona Design System, (Barcelona: GRACMON, Epub. Universitat de Barcelona, 2018): 14. https://www.academia. edu/36186480/Art_d\%C3\%A9co_en_Espa\%C3\%B1a_Estilo_y_cultura_de_masas

${ }^{25}$ Fondevila, Art déco català (1909-1936): 90.

${ }^{26}$ Folch i Torres, Santiago Marco. 31 realitzacions: 12.

${ }^{27}$ Aparece referenciado en una bibliografía inédita 3. Sección Bibliográfica. C. Cronología biográfica sobre S. Marco, en Exposició de projectes, plànols i realitzacions de Santiago Marco. Fons FAD en el Museu del Disseny de Barcelona.

${ }^{28}$ Andere Laringa Cuadra, "La Exposición Internacional de Arte Sacro de Vitoria de 1939: un hito artístico en la postguerra española," Ondare: cuadernos de artes plásticas y monumentales, n²5 (Gasteiz: Eusko Ikaskuntza, 2005): 226.

${ }^{29}$ Teresa Bastardes, "Le Boudoir Améthyste. Un conjunto Art Déco de Santiago Marco de 1925," Art Déco. Història, materials i tècniques (Barcelona: Ajuntament de Barcelona, 2018): 54.

${ }^{30}$ Ver fotografías: "Algunes notes sobre la decoració moderna,” D’ací i d'allà, nº 172 (abril 1933) y Josep Mainar, "El modern agenciament d'interiors," Art: publicació de la Junta Municipal d'Exposicions d'Art, Volum 1, n 04 (enero 1934).

${ }^{31}$ El Hall de Santiago Marco se puede ver en la lámina XIII del Catálogo de la Exposición del Mueble de Barcelona de 1923.

${ }^{32}$ Información facilitada por la Dra. Núria Gil.

${ }^{33}$ Fons Rigalt, Museu del Disseny, MDB-3-401-4146. Llibres d'encàrrecs de projectes. Ordenació cronològica.

${ }^{34}$ En el Fondo del FAD se conservan tres vistas del despacho: FAD-FT0012-53-R-I, FAD-

FT0012-54-A-I, FAD-FT0012-54-A-S, mientras que en el Arxiu Mas se conserva una cuarta: Movil 146 de Santiago Marco.

${ }^{35}$ Aunque hoy en día no se conserva el reloj, éste queda documentado en un peritaje que se hizo de la casa en el año 1982 por encargo de la Generalitat de Catalunya a Ramon Lluis Monlleó.

${ }^{36}$ En las fotografías conservadas en el Arxiu Mas se puede observar mejor, que en las conservadas en el fondo del FAD.

${ }^{37}$ En la subasta de la colección de arte de Melcior Colet se vendieron por 625.000 pesetas dos piezas de porcelana de Dresden cuya descripción coincide con las que se observan en las fotografías del despacho. La noticia se puede consultar en La Vanguardia del 24 de junio de 1987, página 14.

${ }^{38}$ En el archivo de Santiago Marco expo118 carpeta 27-28 hay una carta que refleja la relación de amistad entre ambos. Escrita por Campanyà el 25 de abril de 1939 se desprende que Marco no está en un buen momento anímico ni económico, pues tiene que dejar su casa para ir a otra más modesta. Campanyà ya le guarda parte de sus muebles y le indica que puede confiar en él y en Perfecte Llosà. También le anima a volver a Barcelona y retomar su trabajo, pues hay varios clientes que quieren ponerse en contacto con él, entre ellos Antoni Batlló.

${ }^{39}$ Las referencias documentales son: CAM-AL0001-13_001 y CAM_AL0001-13_002.

${ }^{40}$ Salvador Marsal también fue cliente de Santiago Marco. 